\title{
IDENTIDADE DE LUGAR E DE TRABALHO ENTRE TRABALHADORES RURAIS NA FRONTEIRA COTIA-IBIUUNA (SP)
}

\author{
IDENTIDAD DE LUGAR Y DE TRABAJO ENTRE TRABAJADORES \\ RURALES EN LA FRONTERA COTIA-IBIÚNA (SP)
PLACE AND WORK IDENTITY AMONG RURAL WORKERS ON THE COTIA-IBIÚNA BORDER (SP)

\author{
Gustavo Martineli Massola e José Barbosa de Araújo Silva Junior ${ }^{1}$ \\ ${ }^{1}$ Universidade de São Paulo, São Paulo/SP, Brasil
}

\begin{abstract}
RESUMO: Reflexões recentes defendem que tanto o trabalho quanto o lugar perderam centralidade na definição da identidade psicossocial contemporânea. Ao mesmo tempo, são raras as pesquisas que procuram relacionar identidade laboral e de lugar. Este trabalho visa estudar ambos os temas entre trabalhadores agrícolas paulistas. Para isso, foram conduzidas 6 entrevistas semiestruturadas com itens relativos à identidade laboral, à identidade de lugar e ao apego ao lugar, as quais foram gravadas, transcritas e submetidas a análise de conteúdo. As principais categorias encontradas foram mobilidade, vínculos de trabalho, posse da terra e clima. Os entrevistados mostraram, com uma única exceção, forte identidade laboral e de lugar. Alguns entrevistados enfatizaram sua identidade com o lugar, outros, com o trabalho. As falas não distinguiam lugar e trabalho, que apareciam aos participantes como uma unidade fenomênica. Os resultados sugerem que lugar e trabalho mantêm sua centralidade para a identidade psicossocial de certos grupos.
\end{abstract}

PALAVRAS-CHAVE: Psicologia Socioambiental; Psicologia Rural; Psicologia Social do Trabalho; Apego ao Lugar; Identidade de Lugar.

RESUMEN: Reflexiones recientes defienden que tanto el trabajo como el lugar perdieron centralidad en la definición de la identidad psicosocial contemporánea. Al mismo tiempo, son raras las investigaciones que buscan relacionar identidad laboral y de lugar. Este trabajo pretende estudiar ambos temas entre trabajadores agrícolas paulistas. Para ello, se realizaron 6 entrevistas semiestructuradas con ítems relativos a la identidad laboral, a la identidad de lugar y al apego al lugar, las cuales fueron grabadas, transcritas y sometidas al análisis de contenido. Las principales categorías encontradas fueron movilidad, vínculos de trabajo, posesión de la tierra y clima. Los entrevistados mostraron, con una única excepción, fuerte identidad laboral y de lugar. Algunos entrevistados enfatizaron su identidad con el lugar, otros, con el trabajo. Los participantes no distinguían lugar y trabajo, que aparecían como una unidad fenoménica. Los resultados sugieren que lugar y trabajo mantienen su centralidad hacia la identidad psicosocial de ciertos grupos.

PALABRAS CLAVE: Psicología Socioambiental; Psicología Rural; Psicología Social del Trabajo; Apego al Lugar; Identidad de Lugar.

ABSTRACT: Recent reflections argue that both work and place lost centrality in the definition of contemporary psychosocial identity. At the same time, research that seeks to relate work and place identity is rare. This study aims to discuss both themes among agricultural workers from São Paulo. Six semi-structured interviews were conducted with topics related to work identity, place identity and place attachment, which were recorded, transcribed and submitted to content analysis. The main categories encountered were mobility, work links, land tenure and climate. The interviewees showed, with one exception, a strong work and place identity. Some interviewees emphasized their identity with the place, others with the work. Participants did not distinguish place and work, which appeared as a phenomenal unity. The results suggest that place and work maintain their centrality to the psychosocial identity of certain groups.

KEYWORDS: Environmental Psychology; Rural Psychology; Social Psychology of Work; Place Attachment; Place Identity. 


\section{Introdução}

Os municípios de Cotia e Ibiúna são bem próximos do centro paulistano e têm vivido um aumento da importância econômica dos setores industrial e de serviços, quando comparados com o setor agrícola (Deepask, 2015). Ambos os municípios apresentam extensas áreas de preservação permanente de Mata Atlântica, além de serem ocupados por agricultores familiares e pequenas empresas que produzem e vendem verduras, legumes e flores. Desde a década de 1980, houve um acelerado crescimento de bolsões residenciais ocupados por moradores egressos da capital, o que produziu complexas transformações na dinâmica social dos municípios (Savioli, 2008).

O presente trabalho parte da perspectiva da psicologia socioambiental e visa estudar a percepção dos trabalhadores agrícolas da fronteira Cotia-Ibiúna sobre suas formas de trabalho ao longo da vida, comparando-as com sua percepção do entorno ambiental. Com isso, busca contribuir para a compreensão das relações entre "trabalho e ambiente", na forma dos afetos expressos em relação ao "lugar" de habitação, ou seja, sob os constructos da "identidade de lugar" e do "apego ao lugar".

As origens da psicologia ambiental contemporânea remetem à própria história da psicologia social e com ela vêm dialogando, tendo, por exemplo, uma referência central na figura de Kurt Lewin e suas discussões sobre espaço social (Lewin, 1989a) e perspectiva temporal (Lewin, 1989b). Durante algumas décadas, a psicologia ambiental voltou-se para o estudo do ambiente físico e distanciou-se propositalmente da psicologia social. Mesmo assim, a aproximação ocorrida entre ambos os campos a partir da década de 1980 pode ser considerada "esperada", conforme a psicologia ambiental foi se tornando "mais social" (Canter, Jesuino, Soczka, \& Stephenson, 1988, p. 1) pela inclusão de temas como a relação entre lugar e identidade psicossocial, podendo atualmente ser considerada, rigorosamente, uma psicologia socioambiental. Tal psicologia ganhou forte caráter crítico na América Latina, conforme as principais lideranças brasileiras passaram a enfatizar de que não seria possível compreender a crise ambiental e suas consequências psicossociais sem, ao mesmo tempo, fundamentar suas reflexões em uma rigorosa crítica social (Tassara, 2005). Neste sentido, a psicologia socioambiental, em suas vertentes críticas, dialoga com a própria psicologia social crítica.

O apego ao lugar será aqui considerado como "um vínculo afetivo que as pessoas estabelecem com áreas específicas onde preferem permanecer e onde se sentem seguras e confortáveis" (Hernández, Hidalgo, Salazar-Laplace, \& Hess, 2007), e a identidade de lugar, como uma "subestrutura da identidade pessoal construída a partir da interação do indivíduo com seu entorno físico e social", estando relacionada "ao estabelecimento de vínculos emocionais e de pertencimento relacionados aos entornos significativos para o sujeito" (Mourão \& Cavalcante, 2006, p. 208). A importância deste tema está relacionada à recente percepção de que os "lugares", considerados como um local específico que em sua expressão concreta não se iguala a qualquer outro lugar (Devine-Wright \& Clayton, 2010), perdem crescentemente o papel que possuíam nos processos de socialização e na dinâmica social (Castells, 2007). Nos grupos humanos pré-modernos, não se podia separar a dinâmica e a estrutura social dos lugares por eles ocupados. O desenvolvimento das instituições modernas levou o Ocidente a uma situação oposta. A crescente interdependência que marca nossa época em escopo global permite falar no caráter fantasmagórico dos lugares (Giddens, 1991) ou na existência de processos de desterritorialização (Ianni, 
1997), cujos efeitos individuais vão desde uma atitude blasé e indiferente face aos lugares habitados até a um sentimento de alienação e perdimento que, segundo Ianni (1997), marca a psicologia do homem contemporâneo.

Por outro lado, diversos autores atribuem importância psicossocial decisiva aos lugares na formação da identidade psicossocial (Ciampa, 1990). Para Weil (1996), por exemplo, o enraizamento, entendido como "a necessidade mais importante e mais desconhecida da alma humana" (Weil, 1996, p. 411), "vem automaticamente do lugar, do nascimento, da profissão, do ambiente" (Weil, 1996, p. 411, grifos nossos). O mesmo vale para Bosi (1994), que ressalta a importância que o lugar desempenha na memória dos velhos.

Ao mesmo tempo, a tradição marxista, segundo a qual as relações de trabalho são consideradas elementos centrais nos processos de subjetivação dos trabalhadores e na constituição de sua identidade psicossocial (Lima, 2007), é alvo de intensas discussões na contemporaneidade, quando a própria centralidade do trabalho para o mundo social vem sendo questionada. Antunes (1995), por exemplo, defende que o papel ontologicamente central atribuído às atividades laborais por Marx para a existência psicossocial humana segue valendo, ao passo que Gorz (1987) e Offe (1989) criticam a ideia desta permanência, atribuindo à existência social contemporânea um caráter fragmentário que não permitiria que emergisse dos conflitos sociais algo como uma consciência de classe proletária. Por consequência, o papel do mundo do trabalho para a identidade coletiva e psicossocial teria diminuído em importância ao longo dos séculos XX e XXI.

Estudos em psicologia socioambiental raramente se articulam àqueles oriundos da psicologia do trabalho. Implicitamente, porém, ambos os campos são relacionados por meio de conceitos como o de "apropriação", de importância central para a psicologia socioambiental. Este conceito é definido por Cavalcante e Elias (2011) como "um processo psicossocial central na interação do sujeito com seu entorno por meio do qual o ser humano se projeta no espaço e o transforma em um prolongamento de sua pessoa, criando um lugar seu" (p. 63). Ainda segundo as autoras, a origem deste conceito encontra-se na obra de Marx e implica o processo de "autorreconhecimento do sujeito no lugar e nos objetos que escolhe e cria" (p. 64), processo contraposto ao de "alienação", que conota a não identificação do sujeito com os objetos que fabrica. Apropriação reflete uma relação com a natureza mediada pelo trabalho, pela qual a humanidade, por sua própria ação, medeia, regula e controla seu metabolismo com a natureza.

Esta relação, porém, raramente é pesquisada. Valeria a pena investigar se os afetos apresentados por certos grupos face a seus "ambientes" de moradia e trabalho relacionam-se - e como - com os afetos ou cognições que apresentam em relação ao seu cotidiano e às suas "relações de trabalho". O presente trabalho objetiva investigar, em caráter exploratório, tais relações, visando contribuir com as discussões que polemizam o caráter fragmentário da relação dos indivíduos e grupos tanto com seu trabalho quanto com seu ambiente. Para isso, foi elaborado um roteiro contendo questões relativas ao trabalho e ao lugar inspiradas pelos temas elencados anteriormente, visando investigar quanto os entrevistados identificam-se com suas atividades laborais e quanto se apegam ou se identificam com os lugares em que habitam e trabalham.

O local de pesquisa foi escolhido por duas razões: a primeira é a familiaridade de um dos autores com a região, na qual sua família viveu e vem exercendo atividades agrícolas há algumas décadas; a segunda é o fato de que a região parece particularmente exposta a processos de rápida transformação nas relações de trabalho rurais, advindas do impacto 
da especulação imobiliária e de sua transformação em áreas urbanas ou periurbanas, processos esses que acontecem devido à expansão da mancha urbana da região da Grande São Paulo. Pode haver variação nas formas como os moradores estabelecem relações afetivas com os lugares e suas atividades laborais, o que apresenta interesse por permitir a comparação entre distintas formas de identificação com o trabalho e o lugar.

A região rural de Ibiúna tem como forma econômica central a produção agrícola familiar, sendo uma das cidades paulistas com as maiores concentrações de agricultores familiares (Luz, Siqueira, La-Rotta, Miquilin, \& Correa, 2015). Considera-se como agricultura familiar o tipo de trabalho no qual se usa mão de obra familiar, em propriedades não maiores do que 4 módulos fiscais, renda predominantemente originária do trabalho rural, além de a propriedade ser dirigida com o auxílio de familiares (Lei n. 11.326 de 2006). O município possui $1057 \mathrm{~km}^{2}$, sendo que $65 \%$ dos 71.217 moradores habitam a região rural, segundo dados do Instituto Brasileiro de Geografia e Estatística (IBGE, 2009). Já Cotia apresenta extensão territorial total de $323,994 \mathrm{~km}^{2}$, para uma área de produção agropecuária de 4230 ha (IBGE, 2007). Possui um campo de trabalho rural menor, com destaque para a indústria. Estando mais próxima da região metropolitana, sofre maior efeito da pressão imobiliária e maior valorização das propriedades.

Como nosso interesse é investigar processos psicossociais, às vezes sutis e difíceis de delimitar, parece desejável o acesso às elaborações próprias dos participantes sobre os assuntos pesquisados por meio de entrevistas menos estruturadas. Essa pesquisa teve como "objetivo central", assim, verificar, por meio de entrevistas semiabertas, como agricultores da fronteira Cotia-Ibiúna descrevem suas atividades cotidianas, suas relações no trabalho e seu percurso como "trabalhadores rurais" (expressão da identidade psicossocial dos entrevistados na relação intrínseca entre atividade laboral - o "trabalho” - e lugar de identidade psicossocial - o "rural"), e quais são suas percepções sobre o ambiente em que moram e trabalham. Um fenômeno central neste trabalho é o desejo de permanecer ou deixar a região e de permanecer ou deixar o trabalho. Em ambos os casos, como suas percepções sobre o lugar e sobre o trabalho relacionam-se com esse desejo?

\section{Método}

\section{Procedimentos}

O presente estudo foi composto por três etapas. Na primeira etapa, foram realizados levantamentos de dados sociodemográficos da região, e os dados do IBGE constituíram nossa principal fonte. $\mathrm{O}$ segundo momento foi de registros etnográficos, ao longo de três visitas à região com duração de um dia. Foram escolhidos dois pontos de observação, um bar e um pequeno comércio, em que muitos moradores se encontravam e permaneciam por um tempo relativamente longo. Constituíam um dos espaços de lazer e socialização da região estudada. Nesta etapa, foram confeccionados diários de campo retrospectivos, por meio de narrativas que buscavam resgatar o sentido do "dito" nas interações com os moradores (Geertz, 1989). Além disso, essa etapa nos permitiu fazer os primeiros contatos com potenciais entrevistados e conhecer distintas formas de relações com o lugar e com o trabalho. Pudemos identificar alguns perfis de moradores e trabalhadores, entre as quais: (a) agricultores que nasceram no local e ali habitaram por toda a vida; (b) agricultores 
que nasceram no local mas abandonaram as atividades agrícolas em prol de empregos nas regiões urbanas da cidade; (c) agricultores que migraram de outras regiões mas que não tiveram a agricultura como primeira opção, saindo de seu local de origem para trabalhar em atividades urbanas no comércio e na indústria e que, posteriormente, retomaram as atividades rurais como exercidas em sua terra natal; (d) moradores jovens que se dividem em dois grupos: aqueles que veem a atividade rural como uma forma de obter sustento, mas desejam sair da região para conseguir outros tipos de trabalho; e aqueles que desejam manter seu trabalho no contexto rural, apresentando forte identificação cultural com o local. Os participantes foram convidados nesses locais para participar da pesquisa.

$\mathrm{Na}$ terceira etapa, foram realizadas entrevistas semidirigidas, gravadas com o consentimento dos entrevistados (que leram e assinaram termos de consentimento livre e esclarecido - TCLE) e transcritas, em que o foco central era obter informações sobre o trabalho e o ambiente. Foi realizada, com o auxílio do software Atlas.ti, uma análise de conteúdo das entrevistas inspirada nos procedimentos descritos por Bardin (2009), os quais, segundo a autora, podem ser entendidos como um conjunto de análises e técnicas com métodos sistemáticos para a descrição do conteúdo de textos. O corpus empírico foi analisado por meio da derivação, empírica e teórica, de categorias de análise (Hutt \& Hutt, 1974). Priorizou-se na análise a repetição de temas entre as entrevistas, a qual indica um conteúdo semântico que se apresenta em vários momentos ou de forma muito intensa entre as entrevistas.

\section{Instrumento}

Entrevista semiestruturada baseada em um roteiro composto por uma parte inicial com questões sociodemográficas, seguida por 11 perguntas divididas em dois grupos: 6 perguntas relativas ao trabalho (entre as quais "fale sobre as atividades do seu dia relacionadas ao seu trabalho" e "você gosta deste trabalho?”) e 5 perguntas relativas ao lugar (como "por que escolheu essa região?” e "você se sente uma pessoa enraizada aqui?”). As perguntas deveriam permitir ao pesquisador que aprofundasse as respostas.

\section{Local}

As entrevistas ocorreram nas moradias dos entrevistados ou em seus locais de trabalho, de acordo com sua preferência. Dois entrevistados autorizaram a realização da entrevista enquanto trabalhavam em suas estufas, enquanto o restante dos participantes concedeu as entrevistas na sala e cozinha de suas residências.

\section{Participantes}

Procuramos escolher "trabalhadores rurais" habitantes da região, nativos ou migrantes, com idade superior a 18 anos que apresentassem perfis diversos, possibilitando distintas percepções do lugar e do trabalho. Mesmo assim, a maioria foi de migrantes que vivem há muitos anos em São Paulo. Foram convidados sete homens, cinco dos quais aceitaram participar. Das quatro mulheres convidadas, somente uma aceitou. Destes onze convidados, seis eram nativos, mas apenas um homem aceitou participar. O número total de entrevistados foi de seis agricultores, sendo três alagoanos, um paulista, um sergipano e um paranaense, todos com famílias na região pesquisada. Todos os entrevistados tinham 
em comum uma permanência no lugar atual de mais de 10 anos, com um tempo máximo de permanência (de um casal natural de Alagoas) de aproximadamente 35 anos.

Como forma de contextualizar os dados, seguindo a tradição da psicologia socioambiental (Wapner \& Demick, 2002), é útil apresentar um breve perfil de cada entrevistado. O casal ao qual nos referimos anteriormente tem a luta por uma propriedade como um destaque em suas histórias - ambos com mais de 60 anos de idade, só conseguiram recursos para comprar sua propriedade há cinco anos. Márcia tem 61 anos de idade, não tem planos de voltar para sua terra natal e sente-se satisfeita com o local em que mora atualmente, por ser próprio e quitado. Seu esposo, Leonardo, relata sentir-se muito incomodado com a falta de acesso à cidade e de um mínimo de infraestrutura. Aos 66 anos de idade, tem muitos problemas de saúde, principalmente de coluna. Marcos é um sobrinho deste casal, que trabalha como meeiro (sociedade em que os trabalhos e despesas são divididos integralmente pela metade). Aos 36 anos de idade, ainda tem pouca estabilidade financeira e pensa em voltar para sua terra natal, Alagoas, com esposa e filha. Outro entrevistado, Paulo, também com 36 anos de idade, tem uma casa própria e constituiu uma família composta por esposa e filho. Ele não tem planos de voltar para sua terra natal, pois tem muitos vínculos familiares e maior estabilidade financeira em São Paulo. Por fim, Felipe, de 52 anos de idade, já está há mais de 30 anos em São Paulo. É arrendatário de um terreno e tem como meta comprar seu próprio terreno e continuar a trabalhar com sua família, especialmente seu único filho, Fábio, de 25 anos, que também aceitou ser entrevistado. Fábio é natural da região e vê com satisfação o local em que habita.

\section{Resultados e discussão}

As entrevistas tiveram em média 26 minutos de duração. A análise gerou 22 categorias, dispostas na Tabela 1. 


\section{Tabela 1 - Categorias de análise das entrevistas}

- Implicações negativas da gestão pública

- Retorno financeiro do trabalho atual

- Aspectos indesejáveis inerentes ao ofício

- Aspectos importantes para a qualidade e continuidade do trabalho

- Clima como agente na qualidade e no rendimento do trabalho:

- Comparações entre campo e cidade

- Identificação com o lugar atual

- Fatores que atrapalham ou impedem a mobilidade

- Fatores que auxiliam a mobilidade (Presente na fala de somente um dos entrevistados)

- Fatores negativos do lugar

- Fatores positivos do lugar

- Locais onde os entrevistados já moraram e trabalharam

- Motivos para sair do lugar atual

- Preferência de Lugar

- Relações pessoais e familiares

- Relações sociais no trabalho (negativas)

- Relações sociais do trabalho (positivas)

- Rotina de Trabalho

- Permanência e descrições da moradia

- Trabalho no lugar de origem

- Trabalhos anteriores

- Vínculo trabalhista

Um primeiro dado importante é que os entrevistados não se ativeram à divisão entre questões sobre o lugar e questões sobre o trabalho. Ao contrário, lugar e trabalho apareciam amalgamados nas respostas. Desta forma, a divisão analítica entre lugar e trabalho não corresponde à maneira como os trabalhadores rurais entrevistados percebem suas vivências, de tal modo que podemos afirmar que, para eles, chegam a constituir uma unidade fenomênica.

As categorias mais significativas puderam ser organizadas em quatro "famílias" que correspondem a classes semânticas que englobam outras categorias: "mobilidade" (Figura 1), "posse da terra" (Figura 2), "interferências climáticas" (Figura 3) e "vínculo trabalhista e relações de trabalho" (Figura 4). Mais adiante, procuraremos apresentar brevemente como as categorias e as famílias apareceram em cada entrevista individual. 
Figura 1 - Categorias associadas à família "mobilidade”

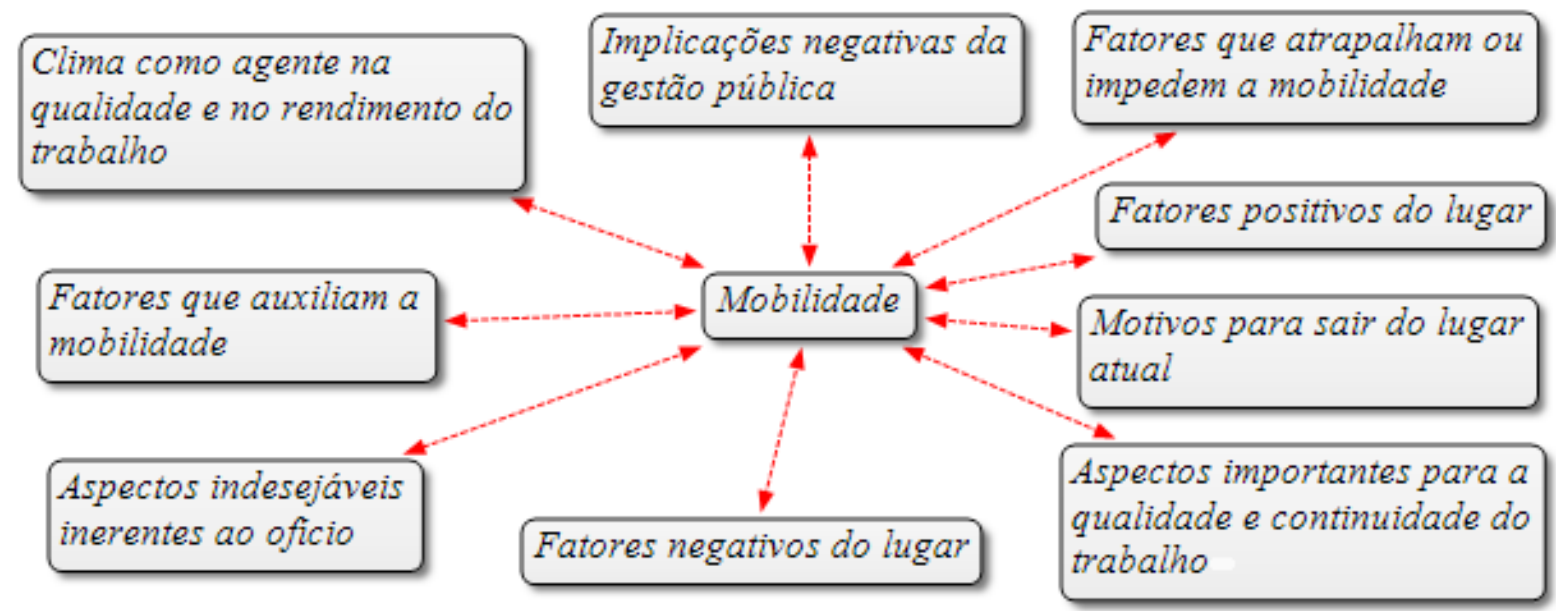

Nove categorias estão vinculadas à família "mobilidade", a qual se relacionou com a percepção dos entrevistados de problemas nos seguintes âmbitos: os processos de trânsito de mercadorias do local de produção até o local consumidor, a qualidade do acesso dos entrevistados a bens e serviços nas cidades (em termos do deslocamento, propriamente, e não do acesso econômico), a interferência na qualidade das vias devido a chuva, sol ou outros fenômenos climáticos, distância e deslocamento de sua moradia até o local de trabalho. Este tema mostrou-se importante para a dinâmica cotidiana do trabalho e para o acesso a serviços nas cidades, bem como para o contato com amigos e familiares. Deve-se destacar que somente um entrevistado observou aspectos positivos na mobilidade local, sendo que todos os outros destacaram apenas pontos negativos sobre o tema.

\section{Figura 2 - Categorias associadas à família "posse da terra"}

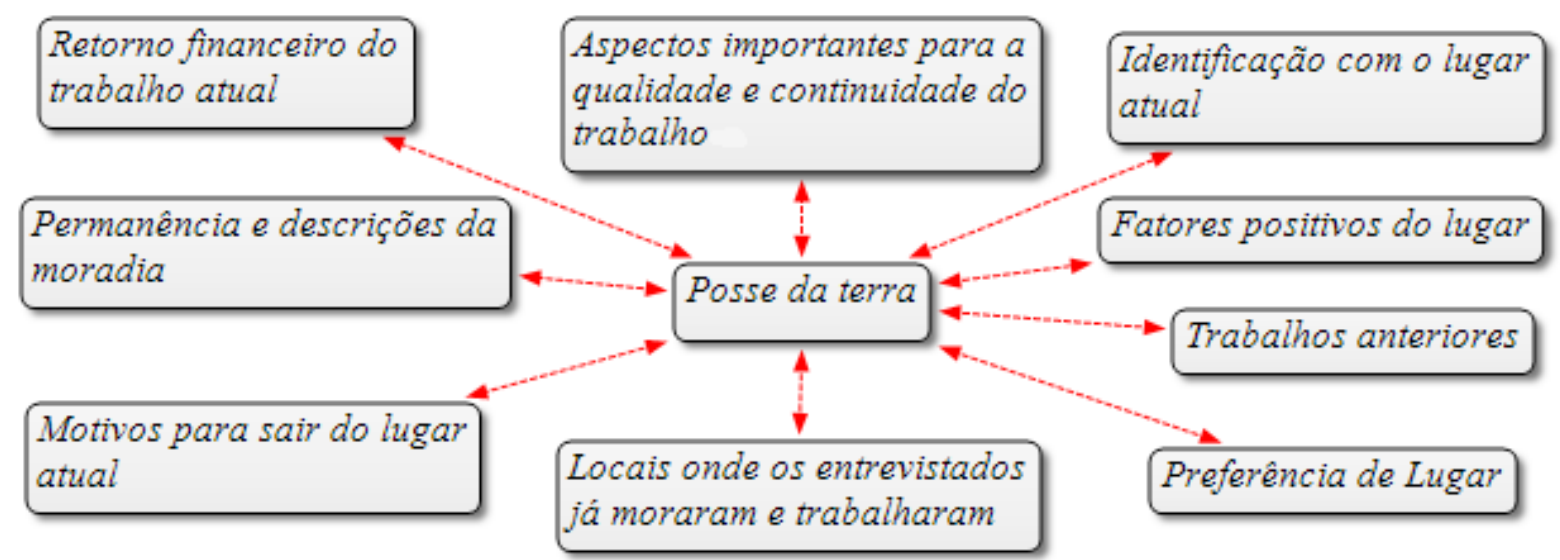

A importância da família "posse da terra" (Figura 2) reside em ser uma variável central na relação com o ambiente, sendo vista de forma distinta pelos entrevistados e permeando as relações trabalhistas e com o ambiente. A posse da terra é, para alguns entrevistados, um motivador para a continuidade no ambiente atual, e, para outros, um componente não essencial para a permanência na região. Estava relacionada também com o tema da pressão imobiliária que ameaça expulsar os trabalhadores agrícolas, sofrida principalmente no local em que Fábio e Felipe produzem, havendo para eles a perspectiva de obter um espaço de produção próprio, além de uma garantia de estabilidade e segurança. 
Figura 3 - Categorias associadas à família "interferências

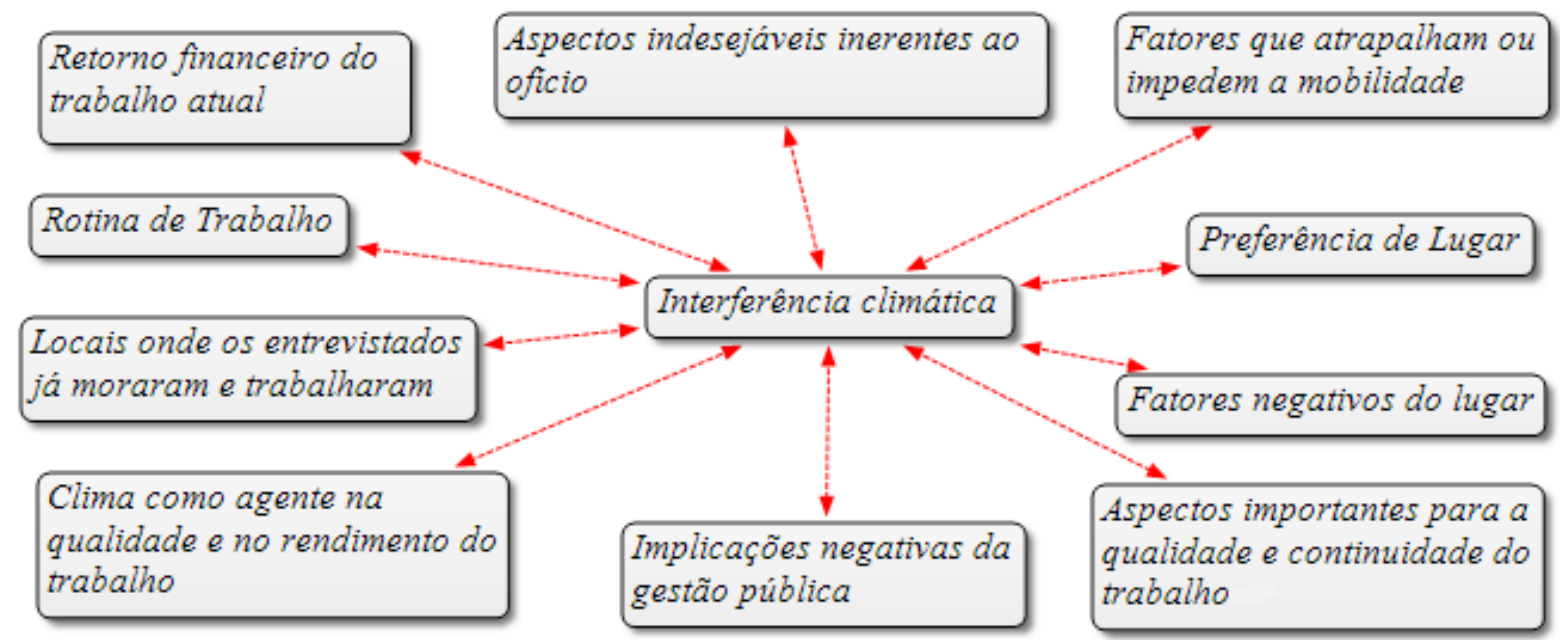

Para todos os entrevistados, ocorreu uma convergência de opiniões a respeito da família "interferência climática", importante em vários aspectos de suas existências, principalmente no trabalho. O clima foi vinculado a dificuldades inerentes ao ofício de agricultor, ou seja, como algo inevitável (efeitos indiretos ou diretos da chuva, do sol, das geadas etc.). Ao mesmo tempo, pode-se induzir uma relação com o apego ao lugar, pois o clima é visto como responsável pela viabilidade do plantio em grande parte do ano na região pesquisada, o que a torna desejável.

Figura 4 - Categorias associadas à família "vínculos trabalhistas e relações de trabalho"

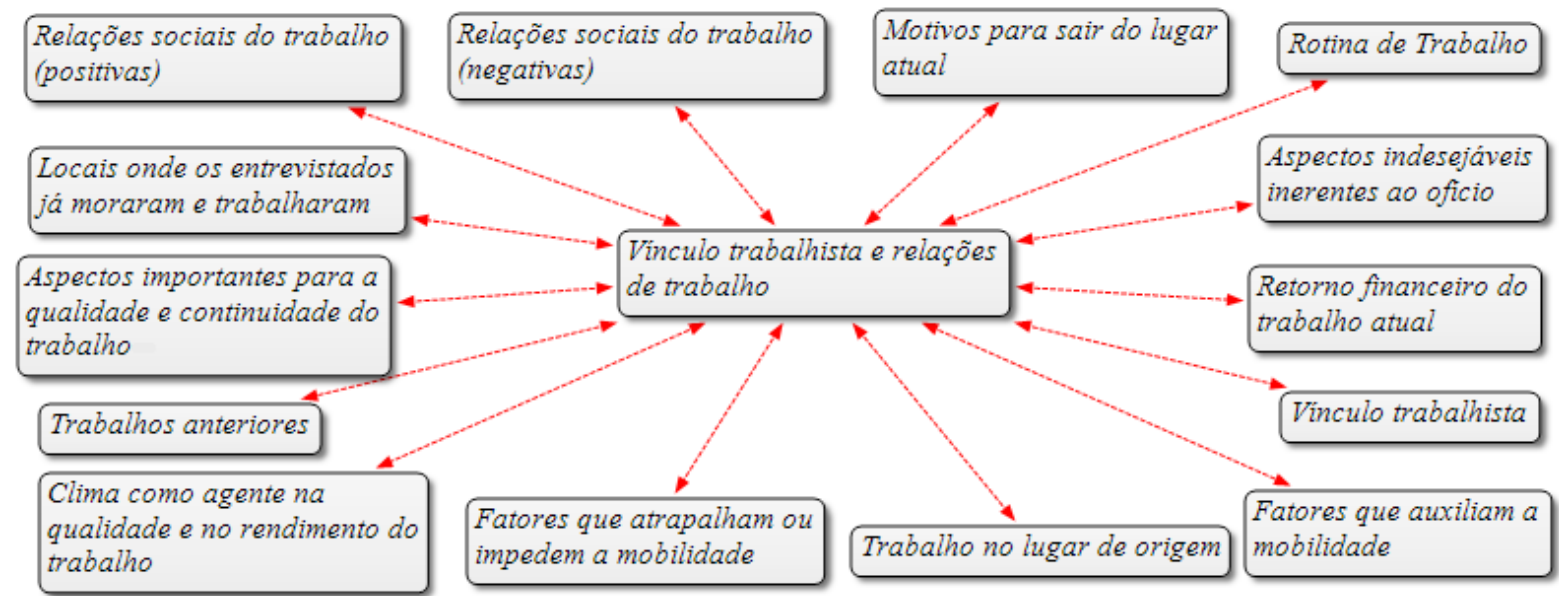

Pelo próprio delineamento das entrevistas, era esperado que grande parte dos conteúdos trazidos fosse relacionada com diferentes aspectos do mundo do trabalho, como se observa na família “vínculos trabalhistas e relações de trabalho" (Figura 4). Cabe destacar, porém, que nem sempre o trabalho aparece nas falas dos entrevistados como um aspecto central para suas vidas. Ao contrário, alguns entrevistados vinculavam suas identidades psicossociais fortemente ao lugar de moradia e trabalho, sendo mais importante permanecer na região independentemente do trabalho realizado, enquanto outros o faziam mais fortemente em relação ao próprio trabalho.

Um ponto importante é o de que os tipos de relações de trabalho são muito próprios do lugar e correspondem às características da agricultura familiar. Pode-se observá-lo na 
importância que os entrevistados dão para as relações pessoais no ambiente de trabalho. Além disso, os vínculos trabalhistas também apresentam relação direta com o lugar, como o de diarista ou meeiro. Este último distingue-se de uma simples parceria na qual se dividem investimentos e lucros: o que se divide é a própria força de trabalho. A mobilidade também deve ser considerada sobre o pano de fundo do lugar concreto: se por um lado os trabalhadores não-proprietários reclamam o direito à mobilidade como forma de acessar os recursos e serviços da cidade e seus locais de trabalho, os proprietários da terra e dos meios de produção veem na melhoria deste aspecto uma forma de aumentar seus lucros e viabilizar a própria produção. Já aos meeiros, este tema interessa sob ambos os aspectos. Mobilidade também foi associada frequentemente ao clima, especialmente pelo impacto das chuvas nas estradas de terra. A dinâmica de trabalho de Fábio e Felipe, que envolve toda a família, mostra um outro importante aspecto do trabalho familiar: não lhes parece necessária uma partilha precisa dos lucros ou sua contratação como funcionários - as relações de trabalho são mais flexíveis de acordo com a demanda e os produtos comercializados. Os conteúdos recorrentes das entrevistas - "posse da terra", "mobilidade", "relações de trabalho" e "interferências climáticas" - relacionam-se, assim, àquele ambiente específico.

Outro ponto essencial para os entrevistados é sua relação de propriedade com a terra em que trabalham. Somente o casal idoso tinha a posse da terra. Marcos, sócio do casal, morava no mesmo terreno por ser meeiro; Paulo, por ser diarista/empreiteiro, sempre trabalhou na região em terrenos de terceiros e, por fim, Felipe e seu filho, Fábio, eram arrendatários do terreno em que trabalhavam juntos. Esse é um aspecto importante na constituição da identidade e do apego ao lugar, além de também ser vinculado à identificação com o trabalho. Leonardo e Márcia, por exemplo, migrantes de Alagoas, e que valorizavam muito suas memórias da infância, falam de um período em que o sustento próprio e o acesso a bens de consumo envolviam grandes dificuldades, surgindo como marcas negativas de seu estado de origem. O fato de viverem em São Paulo há mais de 30 anos, além da posse da terra, implicam uma percepção de maior estabilidade e menor desejo de se mudarem para outro local ou trabalho. Os aspectos da rotina são vistos como satisfatórios, o vínculo que eles têm com seu trabalho é constituinte central de sua identidade, e os processos cotidianos são organizadas pela atividade laboral. A apropriação do lugar pelo trabalho (Cavalcante \& Elias, 2011) se dá ao ponto de ser central nas falas de Leonardo e Márcia, em que o ofício diário e a atual moradia muitas vezes aparecem como unificados.

Seguindo a conceituação de Elali e Medeiros (2011), a atenção a este panorama mais amplo relacionado à idade, história migratória, posse da terra, vinculação com trabalho, período de estadia na região, é necessária para analisar os motivadores multifacetados da vinculação com o ambiente e a identidade de trabalho. Além disso, o caráter dinâmico da interação com o lugar pode ser abordado à luz das noções de "passado internacional" e de "potencial internacional". O passado interacional implica as memórias, as experiências vividas que marcam um vínculo com um determinado local e o potencial interacional implica as possibilidades futuras que um lugar oferece. Marcos, por exemplo, foi o entrevistado que se mostrou menos apegado ao lugar atual, pois, ao contrário dos demais, ainda vê a volta para seu estado de origem como uma forte possibilidade. Ele mostra apreço pelo lugar de origem - "o passado internacional” - e para ele, o local atual mostra poucas potencialidades, especialmente num aspecto que seria central para sua permanência - o trabalho. O retorno financeiro parece-lhe insuficiente, há dificuldades no escoamento da produção, sente uma profunda instabilidade por não ter sua terra e sequer vislumbra a possibilidade de consegui-la. Esses aspectos podem ajudar a compreender sua falta de 
motivação para continuar no lugar. Quando perguntamos se deseja mudar de lugar ou de trabalho, ele responde:

Às vezes sim, mas isso é um projeto sem data marcada, não tenho planos de deixar, ou hoje ou amanhã. Quando surgir algo melhor, a gente né... deixa o emprego, como se diz, e muda de opções. O mundo é feito de opções, achando umas opções que se sinta mais confortável, só que não é uma coisa para hoje ou para amanhã. Pode ser daqui a seis meses, daqui a um ano ou não acontecer. Não acontecer em momento nenhum, e a gente venha a se conformar, que viva daquele jeito, e esqueça o segundo plano. Tudo pode acontecer.

O objetivo dele então passa a ser ter recursos financeiros para manter a casa e a família. O trabalho ganha para ele, pessoalmente, um caráter alienado (e não apenas no sentido teórico-conceitual do termo, que lhe empresta a tradição marxista), pois a atividade laboral não é transformadora, e sua identidade de trabalhador aparece-lhe como opressiva.

Leonardo e Márcia relacionam-se com Marcos na condição de meeiros - marido e mulher, proprietários, recebem 50\% do valor auferido. Essa configuração pode ser analisada de muitas formas: Marcos, por um lado, mais jovem e saudável, produz e trabalha igualmente ao casal que já está com idade mais avançada; por outro lado, pode haver a percepção de que a renda da esposa, Márcia, seria uma "complementação" da mão de obra, insuficiente para ser vista como um terceiro membro na divisão dos lucros (uma estrutura, assim, patriarcal/ machista). Pode-se pensar, porém, que as relações afetivas, de coabitação, façam com que a força de trabalho do casal seja vista como unificada pelo núcleo familiar, e, portanto, não faria sentido pensar em uma forma individualizada de divisão dos recursos.

Evidência do caráter multifacetado da relação com o lugar é o fato de Marcos, a despeito de mostrar um baixo apego ao lugar e um desejo de regressar ao lugar de origem, relatar uma forte identificação, como podemos ver nesse trecho:

eu tô nessa região, então a gente se sente um pouco daqui, já não tem mais um... Até que a gente fala em ir para a terra natal, que é um sonho, de conviver mais uns anos com a família, mas a gente se sente daqui, hoje em dia, a gente tem até mais conhecimento de como é viver aqui. Retornar para o Nordeste e não sabe mais, não sabe mais como vai ser a convivência, como que vai ser a forma, se a gente vai se acostumar ou não vai. Já me sinto um pouco com a cultura daqui, vamos dizer assim, a cultura caipira do agricultor paulista daqui.

Paulo foi o único trabalhador entrevistado que exercia função remunerada para terceiros, com diárias e empreitas, mas que não comercializava ou consumia os produtos de sua atividade. Essa distinção é fundamental para a descrição do grupo participante. No entanto, para o entrevistado, em nenhum momento isso foi sinal de desvalor de seu trabalho ou de sua identidade como trabalhador rural. Esse ponto é importante, pois Paulo se mostrou muito apegado e enraizado ao lugar, mesmo sendo natural de outra região. $\mathrm{Na}$ entrevista, ele valoriza seu ofício atual, pois considera que a região possibilita mais oferta de trabalho quando comparada ao seu estado de origem, onde predominam as produções extensivas de soja e milho. Ser diarista, trabalhar em mais de uma propriedade com um vínculo trabalhista flexível, poderia ser visto como fator de instabilidade no trabalho e baixo apego ao lugar, mas o histórico narrado em sua entrevista, o que inclui relato de trabalho escravo, trabalhos sazonais escassos no Paraná e trabalhos exaustivos e desagra- 
dáveis em granjas, fizeram com que ele visse a posição de diarista como positiva, estável, evidentemente cansativa e com salário baixo, e, no entanto, com qualidade superior à de suas atividades anteriores.

Os dois últimos entrevistados são pai e filho que trabalham juntos na produção de mudarias ornamentais, ervas e temperos, em uma configuração de produção familiar em que esposas e primos também participam, exercendo serviços especializados e distintos. Felipe entende que sua produção agrícola atual não teria mercado em sua terra natal, e não tem desejo de se mudar. Além dos vínculos pessoais, ele percebe ter criado gradativamente uma clientela, o que implica maior estabilidade em seu trabalho. Seu filho, Fábio, foi o único entrevistado natural da região, e, além disso, o mais jovem. Em sua entrevista, ele expressou grande satisfação com o trabalho que realiza, sem absolutamente nenhum plano de sair da agricultura, que ele descreve como um trabalho que possibilita o sustento da família e estabilidade. Juntamente com um apego enorme pelo lugar, ele se identifica muito com o ambiente rural:

Olha, nem imagino [mudar de região]. Meu local é aqui mesmo. Nunca tive vontade de ir trabalhar, morar na cidade, ou sei lá, ir para outro canto. Acho que consigo meu objetivo por aqui mesmo. Nunca sabemos do futuro, mas acho que só uma coisa muito grave, que eu faça obrigado, e não por escolha, para eu sair dessa região, porque se eu sair acho que vou me sentir como uma planta arrancada - vai demorar para ela se recuperar e voltar a crescer.

Assim, é possível observar a importância de outros fatores além do trabalho em si para o sentimento de enraizamento no lugar.

Voltando ao tema da condição legal da atual moradia, devemos nos perguntar: o apego à região está diretamente vinculado à propriedade da terra? Cada entrevista parece indicar uma resposta diferente a essa questão. As entrevistas sugeriram que ser proprietário da terra não é fator central para a continuidade na região. Isto não quer dizer que ser proprietário não tenha importância. Pelo contrário, ser dono do seu lugar é visto como uma forma de se obter maior estabilidade financeira, realizar um sonho e permanecer no local. No entanto, a propriedade da terra em si não indica necessariamente maior identificação e apego. Para alguns entrevistados, esta região apresenta boas possibilidades de gerar capital para um dia conseguir seu próprio terreno, o que constitui um fator motivador para a permanência. Em outras palavras, apropriação do lugar e propriedade sobre a terra relacionam-se dialeticamente para os entrevistados.

Um último ponto é que o trabalhador rural tem como contexto de trabalho um ambiente exposto a condições climáticas que interferem na produção e no seu desgaste físico. Cabe destacar uma distinção feita nas entrevistas entre os danos que a produção sofre pelo clima e o desgaste dos próprios entrevistados. Enquanto o impacto sobre o corpo pela ação do sol, da chuva e do frio é visto como inerente à profissão, sem que haja possibilidades importantes de melhoria, o impacto sobre as mercadorias lhes parece mais preocupante e frustrante. Além do impacto direto sobre a plantação, as implicações indiretas, como o excesso de lama nas estradas, pontes submersas e menor rendimento na colheita, foram vistas por Leonardo, Márcia e Marcos como passíveis de melhoria e até superação, caso houvesse maior apoio dos poderes públicos. O clima também parece ter um aspecto estrutural na rotina de Paulo, pois suas atividades realizadas por diária ou empreitada implicam metas específicas a cumprir. Mesmo para Felipe e Fábio, que produzem em estufas, os efeitos do clima ainda interferem na produção, já que estão em um ambiente isolado, as plantas 
dependem de cuidados, e a mesma cobertura que aquece e protege de chuvas torrenciais ou geadas evita que a planta tenha acesso à chuva, exigindo dedicação diária e contínua.

\section{Considerações finais}

O presente trabalho se desenvolveu no contexto das ruralidades, mais especificamente, da agricultura familiar, e buscou investigar a identidade de trabalhadores rurais com seu trabalho e com seu lugar, comparando-os a fim de discutir a tese segundo a qual há um declínio em ambas as formas de identificação. Para isso, foi elaborado um roteiro de entrevista semiestruturada com duas partes, dedicadas a cada um dos temas.

O primeiro dado refere-se ao fato de os entrevistados não separarem lugar e trabalho, de tal modo que ambas as esferas parecem constituir uma unidade fenomênica. Tal indissociabilidade deveria estimular que outras pesquisas se dedicassem ao estudo das relações possíveis entre psicologia do trabalho e psicologia socioambiental - na prática, parecem ser campos mais próximos do que as tradições de pesquisa deixam ver.

As análises categoriais destacaram 4 grandes áreas semânticas que aglutinam parte significativa das respostas: mobilidade, clima, posse da terra e vínculos de trabalho. Todas as "famílias" de categorias abarcam verbalizações referentes tanto ao lugar quanto às relações de trabalho. Quanto à mobilidade, entendida como necessária tanto para o acesso a bens e serviços quanto para a distribuição de mercadorias produzidas, houve apenas avaliações negativas (com uma exceção). Este dado é significativo quando pensamos que pesquisas realizadas com trabalhadores rurais em outros países da América Latina encontraram respostas muito parecidas (Granada \& Massola, 2016). O clima foi entendido como um fator negativo por levar à eventual perda da produção e por exigir do trabalhador a exposição de seu corpo a condições potencialmente danosas, mas também como um fator positivo, ao explicar a alta produtividade obtida nesta região. As consequências do clima sobre a produção foram relatadas como frustrantes por poderem ser facilmente evitáveis desde que os poderes públicos resolvessem agir. Sobre seu próprio corpo, pareceram aos entrevistados inevitáveis. Talvez possamos ver aqui uma expressão do fetiche da mercadoria, que aparece no processo produtivo como o verdadeiro agente econômico, pondo no polo passivo os trabalhadores que, efetivamente, as produzem (Marx, 2015). A posse da terra não apareceu como essencial para o apego e a identidade de lugar, mas não deixou de interagir dinamicamente com o enraizamento, levando a crer que, para os participantes, propriedade e apropriação relacionam-se dialeticamente. Quanto aos vínculos de trabalho, mostraram-se relacionados por necessidade lógica com processos locais, especialmente pelo fato de muitos colaboradores constituírem vínculos comunitários, na condição de familiares e amigos, ou seja, resgatando-se aqui o sentido originário do termo "comunidade" que remetia, na antropologia do século XIX, diretamente a processos territoriais (Massola, Svartman, Santos, \& Galeão-Silva, 2015).

É digno de nota que, enquanto alguns entrevistados enfatizaram o vínculo com o lugar sobre o vínculo com o trabalho, para outros, o trabalho pareceu central. Apenas um dos entrevistados insinuou baixo apego ao lugar atual, mas isto porque relatou manter forte vínculo com seu lugar de origem. Quando se considera a indissociabilidade entre ambas as esferas, porém, esta distinção parece perder importância, de tal modo que para a maioria deles, identidade de lugar e de trabalho constituem parte fundamental de sua identidade 
psicossocial. Pode-se presumir que uma abordagem adequada tenha que lançar mão de conceitos mais amplos e que abarquem ambos os fenômenos, como o de enraizamento (Weil, 2001). Segundo Svartman (2011), o desenraizamento implica a "impossibilidade de participação no governo do trabalho e impossibilidade de participação criativa nas atividades realizadas, o impedimento de relação com o passado e com o futuro a partir das tarefas e do lugar social ocupado” (p. 223). O enraizamento implica certa relação não apenas com o lugar social, mas, segundo Weil (2001), com o lugar em sentido ambiental e territorial. Vale ressaltar que as conclusões a que chegamos referem-se ao contexto específico do trabalho rural e não podem ser extrapoladas para outras realidades, como a do trabalho fabril, que pode apresentar relações muito distintas entre trabalho e lugar.

Apesar do pequeno número de participantes e do contexto específico em que se desenvolveu, as âncoras laborais e locais parecem seguir, portanto, em certos contextos socioambientais, e ao contrário do que correntes de pensamento consideradas grosso modo como pós-modernas tendem a insinuar - como a ideia de que as pessoas "não sabem mais o que elas são” (Claval, 1999, p. 21), não se identificam mais com suas formas de trabalho (Gorz, 1987) e de que as relações sociais se deem crescentemente em forma de redes (Castells, 2007) -, como componentes importantes da identidade psicossocial contemporânea.

\section{Referências}

Antunes, R. (1995). Adeus ao trabalho? Ensaio sobre as metamorfoses e a centralidade do mundo do trabalho. São Paulo: Cortez.

Bardin, L. (2009). Análise de conteúdo. Lisboa: Edições 70.

Bosi, E. (1994). Memória e sociedade: lembranças de velhos (3a ed.). São Paulo: Companhia das Letras.

Canter, D., Jesuino, J., Soczka, L., \& Stephenson, G. (1988). Environmental Social Psychology. Boston: Kluwer Academic Publishers.

Castells, M. (2007). A sociedade em rede(10a ed.). São Paulo: Paz e Terra.

Cavalcante, S. \& Elias, T. F. (2011). Apropriação. In S. Cavalcante \& G. A. Elali (Eds.), Temas básicos em Psicologia Ambiental (pp. 63-69). Petrópolis, RJ: Vozes.

Ciampa, A. (1990). A estória do Severino e a história da Severina (2a ed.). São Paulo: Brasiliense.

Claval, P. (1999). O território na transição da pós-modernidade. GEOgraphia, 1(2), 7-28.

Deepask. (2015). Confira o PIB - Produto Interno Bruto da sua cidade - COTIA, SP. Recuperado de http://www.deepask.com/goes?page=cotia/SP-Confira-O-PIB---Produto-Interno-Bruto---noseu-municipio

Devine-Wright, P. \& Clayton, S. (2010). Introduction to the special issue: Place, identity and environmental behaviour. Journal of Environmental Psychology, 30(3), 267-270. https://doi. org/10.1016/So272-4944(10)00078-2

Elali, G. A. \& Medeiros, S. T. F. (2011). Apego ao lugar. In S. Cavalcante \& G. A. Elali (Eds.), Temas básicos em Psicologia Ambiental (pp. 53-62). Petrópolis, RJ: Vozes.

Geertz, C. (1989). A interpretação das culturas. Rio de janeiro: LTC.

Giddens, A. (1991). As consequências da modernidade (5a ed.). São Paulo: UNESP.

Grorz, A. (1987). Adeus ao proletariado: para além do socialismo. Rio de Janeiro: Forense Universitária. 
Granada, H. \& Massola, G. M. (2016). Comparação entre representações campo-cidade de habitantes da zona rural de Buga (Colômbia) e investigações e reflexões críticas brasileiras sobre o tema. Revista de Educação Técnica E Tecnológica Em Ciências Agrícolas, 11(14), 85-106. Recuperado de http://www.ufr.j.br/SEER/index.php?journal=retta\&page=article\&op=view\&path\%5B\%5D $=3377 \&$ path $\% 5 \mathrm{~B} \% 5 \mathrm{D}=2058$

Hernández, B., Hidalgo, M. C., Salazar-Laplace, M. E., \& Hess, S. (2007). Place attachment and place identity in natives and non-natives. Journal of Environmental Psychology, 27(4), 310-319. https://doi.org/10.1016/j.jenvp.2007.06.003

Hutt, S. J. \& Hutt, C. (1974). Observação direta e medida do comportamento. São Paulo: EPU; EDUSP.

Ianni, O. (1997). A sociedade global (5a ed.). Rio de Janeiro: Civilização Brasileira.

Instituto Brasileiro de Geografia e Estatística [IBGE]. (2007). Pesquisa nacional por amostra de domicílios. Brasília, DF: Autor. Recuperado de http://www.ibge.gov.br/home/estatistica/ populacao/trabalhoerendimento/pnad2007/default.shtm

Instituto Brasileiro de Geografia e Estatística [IBGE].(2009). Pesquisa Nacional por Amostra de Domicílios - PNAD - 2009. Brasília, DF: Autor.

Lewin, K. (1989a). Experimentos com espaço social. In Problemas de dinâmica de grupo (pp. 87-99). São Paulo: Cultrix.

Lewin, K. (1989b). Moral e perspectiva temporal. In Problemas de dinâmica de grupo (pp. 119-140). São Paulo: Cultrix.

Lima, M. E. A. (2007). Trabalho e identidade: uma reflexão à luz do debate sobre a centralidade do trabalho na sociedade contemporânea. Educação Eீ Tecnologia, 12(3), 05-09. Recuperado de http://seer.dppg.cefetmg.br/index.php/revista-et/article/view/107/109

Luz, V. G., Siqueira, C. E. G., La-Rotta, E. I. G., Miquilin, I. O. C., \& Correa, H. R. (2015). (In)segurança alimentar e nutricional, autopercepção da saúde e uso de agrotóxicos: o caso dos agricultores familiares de Ibiúna, São Paulo. Segurança Alimentar E Nutricional, 22(2), 729-741. Recuperado de https://periodicos.sbu.unicamp.br/ojs/index.php/san/article/ view/8642503/10024

Marx, K. (2015). O Capital. Crítica da Economia Política. (R. Enderle Trad., Vol. I). São Paulo: Boitempo.

Massola, G., Svartman, B., Santos, A., \& Galeão-Silva, L. (2015). Quilombos e conflitos territoriais no Brasil: o caso do Vale do Ribeira, SP. In A. Lima, D. Antunes, \& M. Calegare (Eds.), Psicologia Social e os atuais desafios ético-políticos no Brasil (pp. 350-72). Porto Alegre: ABRAPSO.

Mourão, A. R. T. \& Cavalcante, S. (2006). Identidade de lugar. In S. Cavalcante \& G. A. Elali (Eds.), Temas básicos em Psicologia Ambiental (pp. 208-2 16). Petrópolis, RJ: Vozes.

Offe, C. (1989). Trabalho: a categoria-chave da sociologia? Revista Brasileira de Ciências Sociais, 4(10), 3-4. Recuperado de http://portal.anpocs.org/portal/index.php?option=com content\&view $=$ article\&id $=227: \mathrm{rbcs}-10 \&$ catid $=69: \mathrm{rbcs} \&$ Itemid $=399 \# 1$

Savioli, M. L. (2008). A cidade e a estrada: as transformações urbanas do município de Cotia ao longo da rodovia Raposo Tavares. Pós (São Paulo), 22, 106-121. Recuperado de http://www. revistas.usp.br/posfau/article/viewFile/43535/47157

Svartman, B. P. (2011). Trabalho e desenraizamento: um estudo sobre o sofrimento psicossocial gerado pela organização do trabalho fabril. Psicologia em Revista, 20(2), 22 1-244. Recuperado de https://revistas.pucsp.br/index.php/psicorevista/article/viewFile/10342/7721

Tassara, E. (2005). Psicologia ambiental e futuro - reflexões geopolíticas sobre política ambiental. Psicologia USP, 16(1/2), 281-287. 
Wapner, S. \& Demick, J. (2002). The Increasing Contexts of Context in the Study of Environment Behavior Relations. In R. Bechtel \& A. Churchman (Eds.), Handbook of environmental psychology (pp. 3-14). New York: John Wiley \& Sons.

Weil, S. (1996). O desenraizamento. In E. Bosi (Ed.), A condição operária e outros estudos sobre a opressão (pp. 407-440). Rio de Janeiro: Paz e Terra.

Weil, S. (2001). O enraizamento. Bauru, SP: Editora da Universidade do Sagrado Coração.

\section{GUSTAVO MARTINELI MASSOLA \\ https://orcid.org/0000-0002-1601-9211}

Professor do Departamento de Psicologia Social e do Trabalho do Instituto de Psicologia da USP. Editor-chefe da revista Psicologia USP e editorcolaborador da revista International Perspectives in Psychology. Coordena o Programa de Pós-Graduação em Psicologia Social da mesma instituição.

Endereço institucional: Avenida Prof. Mello de Morais, 1721, Butantã, São Paulo - SP, 05508-030 - Bloco A, sala 139.

Email: gustavomassola@usp.br

\section{JOSÉ BARBOSA DE ARAÚJO SILVA JUNIOR}

\section{https://orcid.org/0000-0003-0126-3921}

Psicólogo graduado pelo Instituto de Psicologia da Universidade de São Paulo. Pós-graduando em Psicologia da Saúde pela Secretaria Municipal de Saúde da Prefeitura de São Paulo.

E-mail: josebarbosa2704@gmail.com

Submissão: 29/06/2017

Revisão: 06/12/2018

Aceite: 17/12/2018

Concepção: G.M.M; J.B.A.S.J.

Coleta de dados: J.B.A.S.J.

Análise de dados: G.M.M; J.B.A.S.J.

Elaboração do manuscrito: G.M.M; J.B.A.S.J;;

Crítico revisões de conteúdo intelectual importante: G.M.M; J.B.A.S.J.

Aprovação final do manuscrito: G.M.M; J.B.A.S.J.

Financiamento: Não se aplica.

Consentimento de uso de imagem: Não se aplica. 